\title{
El patrimonio arquitectónico defensivo en la provincia de Huelva: protección, conservación y difusión
}

Carlos Alberto Rivas Quintero

Rocío Fernández-Baca Galante Remedios Gámiz Aguilera

Delegación Provincial de Cultura de Huelva

\section{Resumen}

Aproximación a la problemática que supone la protección, conservación y difusión del patrimonio arquitectónico defensivo en la provincia de Huelva. Tras una introducción sobre el devenir histórico de dicho patrimonio se detallan las últimas actuaciones en materia de protección y conservación llevadas a cabo por la Consejería de Cultura a través de su Delegación Provincial en Huelva sobre este patrimonio, aportándose finalmente una serie de propuestas para su aprovechamiento como recurso cultural vivo.

\section{Palabras clave}

Arquitectura defensiva / Arquitectura militar / Arquitectura medieval / Arquitectura moderna / Castillos / Baluartes / Fortificaciones / Murallas / Torres almenaras / Protección / Conservación / Difusión / Rutas de arquitectura defensiva / Delimitación de entornos
Los castillos, baluartes, torres y murallas de la provincia de Huelva forman un rico y variado patrimonio arquitectónico defensivo, fraguado por culturas muy diferentes. Durante la Antigüedad los romanos, fundamentalmente, dejaron en la provincia una red de infraestructuras $y$ fortificaciones heredada posteriormente por los musulmanes y los cristianos durante la Edad Media. Es precisamente en este período histórico cuando se produce el momento de máximo esplendor de dicho legado debido, inicialmente, a las luchas entre los reinos cristianos y musulmanes, $y$, posteriormente, por los enfrentamientos entre las coronas castellana y portuguesa por el control de dicho territorio.

Con la invasión musulmana en el 7 I I el reaprovechamiento de las fábricas preexistentes resultó especialmente importante cuando aún el estado estaba dotado de medios precarios. Pero poco a poco las nuevas necesidades defensivas se tradujeron en la edificación de nuevas construcciones, especialmente desde el califato, cuando ya se hallaba definida la defensa del territorio. En el siglo XI se derrumba el califato e irrumpen los reinos de taifas, cuya debilidad frente a los reinos cristianos hace que decidan solicitar apoyo a los almorávides, que llegan a Al-Andalus en el 1090. La amenaza cristiana hace que los almorávides emprendan una serie de proyectos defensivos culminados posteriormente por los almohades, llegados a la Península en I I47, comenzando entonces una época en la que de nuevo se reaprovechan antiguas fortificaciones romanas como Niebla, Aro-
Huelva: Plano de situación de los castillos de la banda gallega

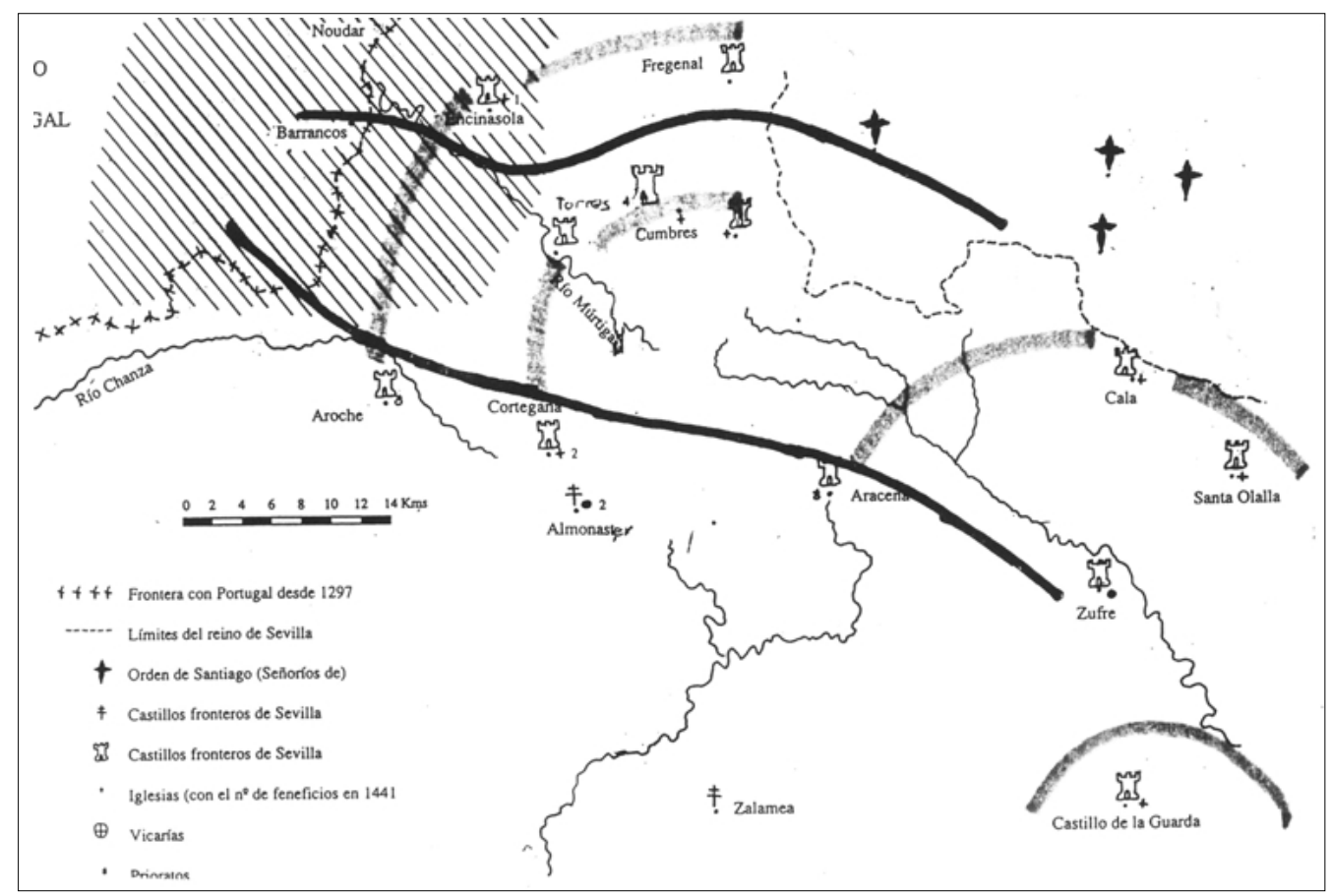


che y Cortegana, y se levantan castillos de nueva planta como los de Aracena, Zufre y Cala.

A mediados del siglo XIII el poder almohade se derrumba dando paso a la dominación cristiana en la zona, convirtiéndose la provincia de Huelva en una frontera peligrosa debido a las pretensiones del reino portugués por su conquista. Para la defensa del territorio, el Concejo de Sevilla reaprovechará los castillos y fortalezas musulmanas, estableciéndose un cinturón defensivo conocido como "la Banda Gallega", compuesto por tres líneas defensivas: la primera definida por los castillos de Aroche, Encinasola y Fregenal de la Sierra; la segunda por los de Torres (en el municipio de Cumbres de San Bartolomé), Cortegana y Cumbres Mayores; y la tercera por los de Aracena, Cala y Santa Olalla del Cala. Además de reacondicionarse durante esta época los viejos castillos musulmanes, es preciso señalar que en 1293 Sancho IV manda construir los castillos de Cumbres Mayores y Santa Olalla del Cala. Dicha política defensiva no se va a ceñir exclusivamente a edificios puramente militares sino también a la construcción de iglesias fortificadas como la de San Bartolomé de Villalba del Alcor.

Posteriormente, en la Edad Moderna, se continuó desarrollando en la zona una política defensiva motivada por la prolongación del conflicto hispano-luso. Se plantea un cambio radical en la concepción de la arquitectura militar debido al avance de la artillería, que hacía obsoleto el anterior sistema defensivo medieval, creándose nuevos modelos de fortificación, destacando los baluartes. Aunque a partir de | 580 la unificación de las dos coronas bajo Felipe || supuso un período de relativa paz, con la independencia de Portugal en 1640 se reanudan los enfrentamientos armados. Son momentos de intermitentes saqueos de las poblaciones onubenses: en I64II 642 Aroche, en 1643 Paymogo, en 1644 Santa Bárbara de Casa, en 1666 Puebla de Guzmán, etc.

En esta coyuntura general se potencian las fortificaciones en la zona del Andévalo, estableciéndose un programa defensivo que no pudo cumplirse en muchas ocasiones. En el siglo XVI se construyen los Fuertes de San Felipe y de San Juan en Encinasola, y el Baluarte de las Angustias de Ayamonte. En 1642 se construye el Castillo de San Marcos de Sanlúcar de Guadiana y hacia 1668 el Castillo de Paymogo, construcción abaluartada poligonal que albergará en su interior a la Iglesia Parroquial de Santa María Magdalena. Dicho conflicto se prolongará hasta la Guerra de Sucesión Española, quedando definitivamente zanjado tras el Tratado de Lisboa de 1926 en el que se fija la frontera hispano-lusa en la zona de la Sierra de Huelva. Igualmente desde finales del siglo XVI hasta algo avanzada la siguiente centuria se construyeron a lo largo del litoral onubense una serie de torres almenaras para hacer frente a las cada vez más habituales incursiones de piratas berberiscos.

Posteriormente, en el siglo XIX se produce un proceso de abandono generalizado de este patrimonio

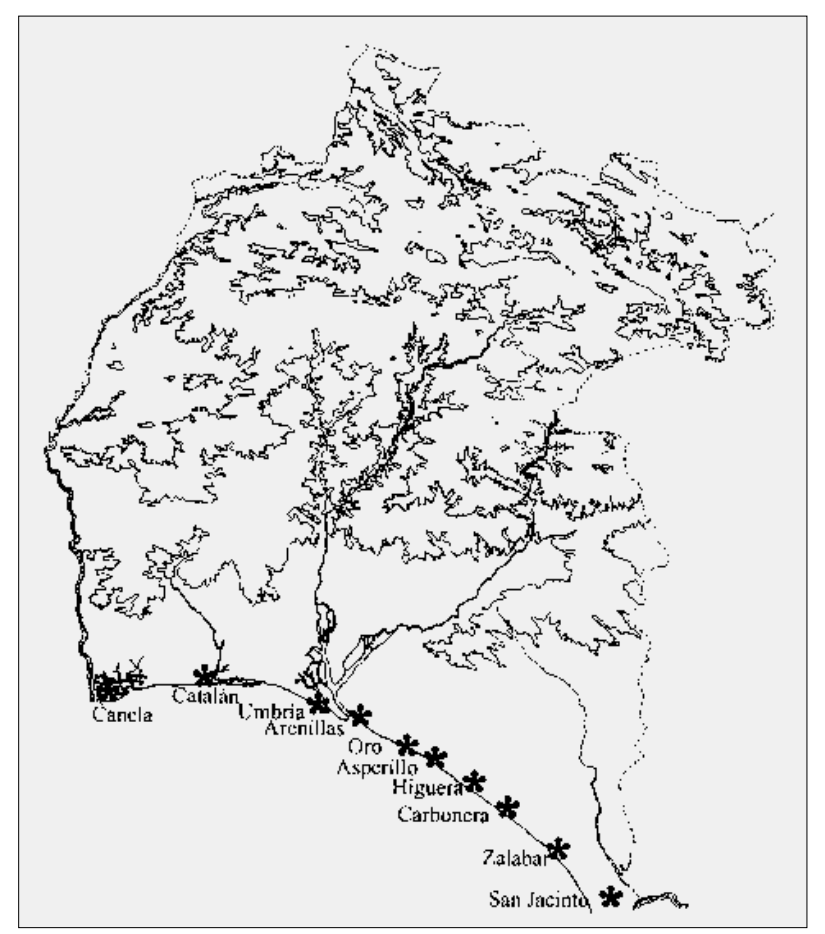

defensivo lo que provocará la ruina e incluso la total desaparición de algunos castillos como el de Huelva, utilizado como cantera. Del mismo modo se producen sucesos tan lamentables como la voladura en 1812 del Castillo de los Guzmanes de Niebla, realizada por el mariscal francés Soult con motivo de la Guerra de la Independencia. El uso inadecuado que en muchos casos han tenido estos edificios ha incidido negativamente en su conservación como ha sucedido con el Castillo de Santa Olalla del Cala, utilizado como cementerio desde el siglo XVIII hasta 1916, lo que ha debilitado notablemente sus muros; el Castillo de Almonaster la Real, que alberga en su interior desde |89| una plaza de toros realizada con los materiales de su cerca; el Castillo de Cala, utilizado no hace mucho para guardar ganado; o el Castillo de Cartaya, adaptado en el siglo XIX como cementerio y en 1872 como depósito de carbón y madera, habiéndose utilizado posteriormente también como plaza de toros y almacén. Pese a ello, los castillos y fortalezas de la provincia de Huelva continúan siendo hitos referenciales del paisaje de muchos pueblos onubenses. Actualmente el patrimonio arquitectónico defensivo provincial está siendo objeto de una creciente atención, realizándose numerosos estudios y actuaciones por parte de la Consejería de Cultura a través de la Delegación Provincial de Huelva para su protección, conservación y difusión, con el objetivo de su efectiva puesta en valor como recurso cultural.

En materia de PROTECCIÓN se ha realizado la documentación técnica necesaria para la declaración de los entornos de las torres almenaras de la costa onubense y de los castillos de Cala, Cartaya, Cortegana, Cumbres de San Bartolomé y Santa Olalla del Cala.

Los castillos de España quedaron bajo la protección del Estado, cualquiera que fuese su estado de ruina,
Huelva: Plano de situación de las torres almenaras 


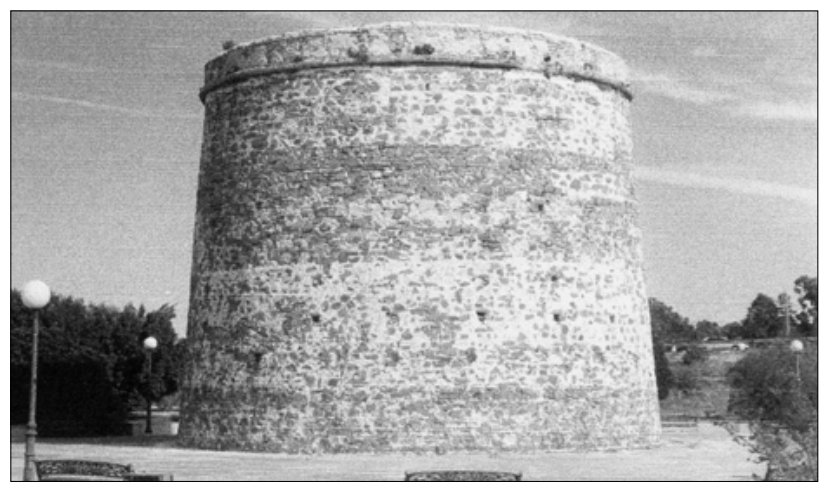

Huelva: Torre de la Arenilla (Palos de la Frontera) por el Decreto del Ministerio de Educación Nacional de 22 de abril de 1949, publicado en B.O.E. de 5 de mayo del mismo año. Con posterioridad se elaboró, conforme estaba previsto en el Decreto, un Inventario de Protección de los Monumentos Militares, en el que se registraron casi 5.200 inmuebles, incluyéndose no sólo los castillos sino también otras tipologías de arquitectura militar. En dicho inventario quedaron incluidas las torres almenaras del litoral onubense y los castillos anteriormente citados. Posteriormente, de acuerdo a lo establecido en la Disposición Adicional Segunda de la Ley 16/85, de 25 de junio, de Patrimonio Histórico Español, todas estas construcciones militares han pasado a tener la consideración de Bien de Interés Cultural, categoría Monumento.

La delimitación de los entornos de las torres almenaras de la costa onubense y de los castillos de Cala, Cartaya, Cortegana, Cumbres de San Bartolomé y Santa Olalla del Cala se ha realizado en cumplimiento del artículo II.2 de la mencionada Ley de Patrimonio Histórico Español, en el que se obliga a los inmuebles declarados como B.I.C. a tener delimitado su respectivo entorno de protección, y en consonancia con el artículo 29.2 de la Ley |/|991, de 3 de julio, de Patrimonio Histórico de Andalucía en el que textualmente se expresa que "el entorno de los bienes declarados de interés cultural podrá estar constituido tanto por los inmuebles colindantes inmediatos como por los no colindantes o alejados, siempre que una alteración de los mismos pudiera afectar a los valores propios del bien que se trate, a su contemplación, apreciación o estudio". La delimitación de dichos entornos se realiza para protegerlos de futuras actuaciones que puedan hacer peligrar su integridad física y correcta visualización, máxime teniendo en cuenta que en el caso de las primeras se encuentran en una zona, el litoral onubense, de gran incidencia del sector turístico. En todos los casos se ha tenido en cuenta en la delimitación de los entornos afectados criterios visuales, la condición del espacio cercano al inmueble, un análisis histórico de la zona donde se ubica y un estudio de la condición tutelar tanto de los inmuebles que nos ocupan como del espacio que los rodean.

El marco político que propició la construcción de las torres almenaras de la costa de Huelva se relaciona con la situación de inseguridad que vivía dicha zona durante la Edad Moderna con el peligro intermitente de las incursiones piráticas berberiscas. Esta empresa fue encargada inicialmente al Capitán General de Artillería D. Francés de Álava. Pero el reconocimiento del terreno y el dictamen de las provisiones fue realizado por D. Luis Bravo de Lagunas, que dictó los sitios más indicados para estas construcciones en 1576. Su informe no fue respetado en su integridad, sufriendo variaciones cuando en 1588 se envió a Juan Pedro Livadote a hacerse cargo de las fábricas de las torres, suprimiéndose algunas de ellas. Debido a problemas de financiación, la ejecución del proyecto sufrió un considerable retraso. Así, el proyecto concebido inicialmente durante el reinado de Felipe II se ejecutó en su mayoría durante el gobierno de Felipe IV, finalizándose en 1638.

Las torres almenaras construidas en la costa onubense, de las que se ha delimitado su respectivo entorno de protección, fueron, de este a oeste, la Torre de San Jacinto (Almonte), de Zalabar (Almonte), de la Carbonera (Almonte), de la Higuera (Almonte), del Asperillo (Almonte), del Río del Oro (Almonte), de la Arenilla (Palos de la Frontera), de Punta Umbría, del Catalán (Lepe) y Canela (Ayamonte). Presentan similares características arquitectónicas, constando de cuerpo troncocónico y estando la mayoría de ellas preparadas para utilizar artillería. La Torre de Punta Umbría y la del Catalán presentan una mayor complejidad constructiva al poseer dos cámaras superpuestas.

Pero una vez desaparecido en el siglo XIX el problema de la piratería berberisca en la zona estas torres fueron paulatinamente abandonas, lo que ha condicionado su actual estado de conservación, en algunos casos muy deficiente. La propia dinámica litoral de la costa ha hecho que algunas de ellas estén actualmente muy alejadas del mar, como la Torre del Catalán, o dentro de éste, como la Torre de la Higuera. En este sentido las que presentan mejor estado de conservación son las torres de San Jacinto, de la Carbonera, de la Arenilla, de Punta Umbría, del Catalán y Canela.

La actual situación geográfica dispar que presentan las torres almenaras de la costa de Huelva ha motivado que no se siga un criterio uniforme para delimitar sus respectivos entornos. Así, en algunos casos se ha definido un polígono con coordenadas U.T.M. debido, entre otros aspectos, a la presencia en algunas torres de restos arqueológicos de poblados de pescadores en la zona asociados a los inmuebles -esta forma de proceder se ha seguido en la Torre de San Jacinto, de Zalabar, de la Carbonera, del Catalán y Canela-. En otros casos se ha considerado no delimitar el entorno por encontrarse en dominio marítimo y en la Zona de Protección del Mar Litoral, dependiente de la Demarcación de Costas del Ámbito Atlántico Occidental -es el caso de la Torre de la Higuera, Torre del Asperillo y Torre del Río del Oro-. En el caso de la Torre de la Arenilla se ha optado por incluir completa la manzana no urbanizada sobre la que se inserta el 
inmueble, delimitada por viales de asfalto, definiéndose ésta a través de coordenadas U.T.M. debido a la inexistencia de planos catastrales que permitan identificar la parcela afectada por la delimitación. Solamente en un caso, la Torre de Punta Umbría, se han seguido los criterios que habitualmente se utilizan para delimitar los entornos de inmuebles insertos dentro de cascos urbanos, incluyéndose las parcelas y espacios públicos que mantienen una relación espacial y visual con la torre, y cuya alteración podría dañar su correcta percepción.

Con respecto a la delimitación de los entornos de los castillos anteriormente citados es preciso señalar que los castillos de Cala, Cortegana, Cumbres de San Bartolomé y Santa Olalla del Cala pertenecían al sistema defensivo denominado de la "Banda Gallega". La mayoría de estos castillos tienen su origen en época musulmana, siendo posteriormente reutilizados por los cristianos, salvo el Castillo de Santa Olalla del Cala, realizado en época de Sancho IV. Por su parte, el Castillo de Cartaya fue construido a comienzos del siglo XV por Pedro de Zúñiga, señor de Gibraleón, para vigilar y defender el paso del río Piedras, cuyo control pretendía Alfonso de Guzmán, señor de Lepe. Su construcción originó el actual núcleo de Cartaya, sirviendo posteriormente como refugio de la población ante los ataques de los piratas berberiscos.

En la delimitación del entorno de estos castillos se han adoptado tres criterios básicos: incluir las parcelas cuyas fachadas están enfrente de alguna de las fachadas del B.I.C. o, en su caso, incluir las parcelas rústicas que se encuentran en contacto directo con el B.I.C. y que forman parte del paisaje existente; incluir los espacios públicos cuyas dos fachadas correspondan a parcelas incluidas dentro de la delimitación del entorno del B.I.C.; e incluir aquellas parcelas que por homogeneidad en la delimitación y por la incidencia visual sobre el B.I.C. así lo merezcan. Se han incluido, por tanto, todas aquellas parcelas catastrales donde la alteración de sus fachadas repercutiría negativamente en la conservación, correcta percepción y uso del inmueble. Dicha alteración se refiere tanto a la modificación de su altura, alineaciones, cubiertas y volumetría, que podría interponerse en la limpia visión del conjunto desde sus diversas perspectivas o dificultar el desempeño de sus funciones, como a las posibles reformas de fachada que incluyan cambios de materiales, formas o sistemas constructivos y que supondrían un posible peligro de deterioro en el monumento, rompiendo su unidad estética con el entramado circundante.

En materia de CONSERVACIÓN se está siguiendo una metodología común a toda restauración arquitectónica, consistente en la realización inicial de estudios previos, la posterior elaboración del proyecto de conservación y por último la ejecución de dicho proyecto.

Entre los castillos en los que se están efectuando los estudios previos para su posterior restauración están

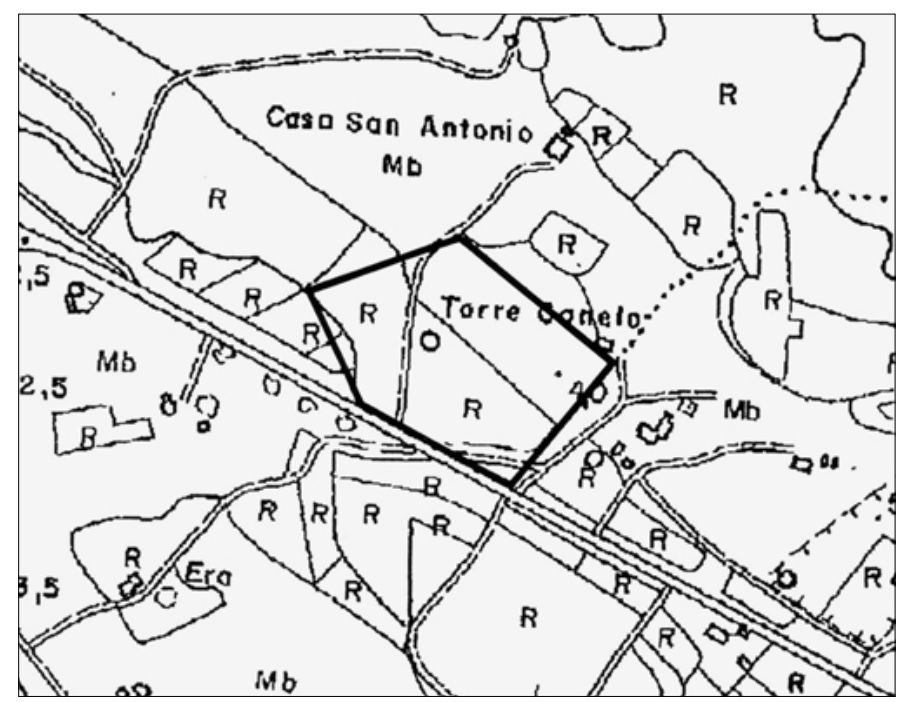

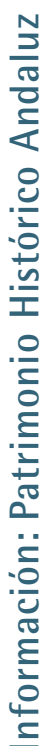

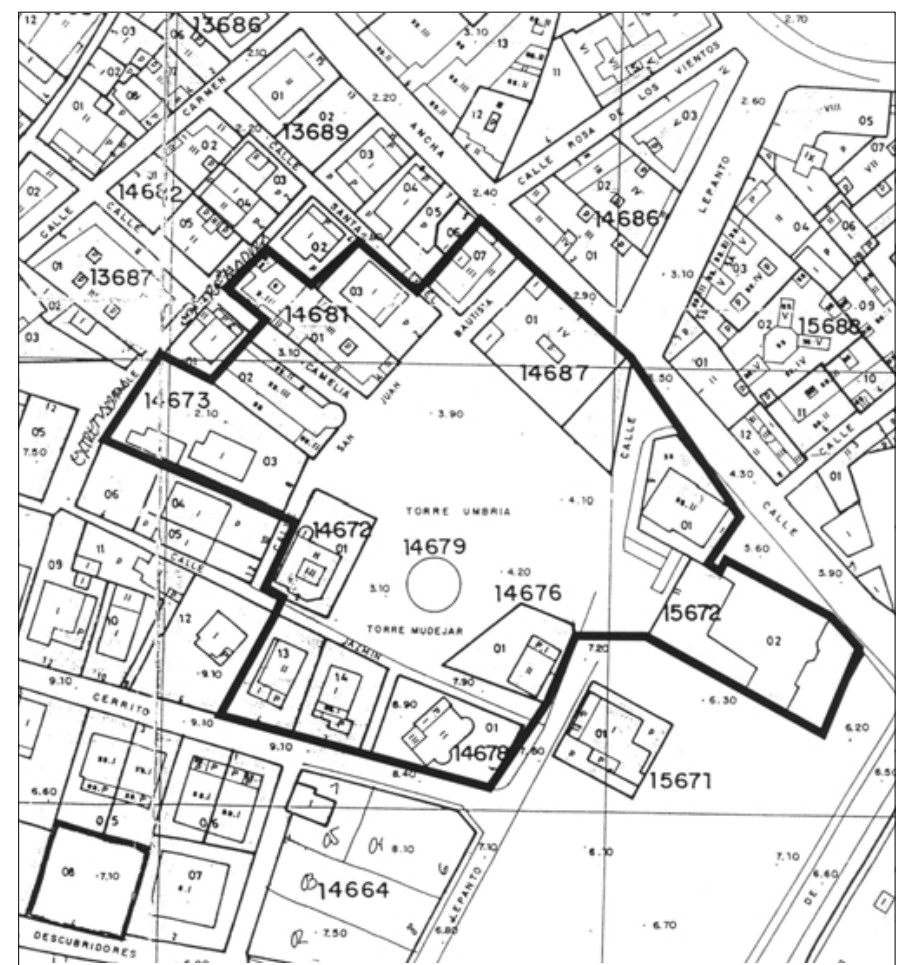

los de Cala, Santa Olalla del Cala y Cumbres de San Bartolomé, consistiendo dichos trabajos en estudios arqueológicos, levantamientos planimétricos y topográicos, así como análisis de materiales constructivos.

Dentro de la arquitectura defensiva de la provincia hay que destacar el carácter monumental y la importancia histórica de las murallas y la ciudad de Niebla, cuya situación estratégica en un cruce de caminos la convirtió en centro de distribución del mineral de las Minas de Riotinto. Se tienen noticias de asentamientos desde la época protohistórica a oriente del recinto actual cuya posterior ocupación romana supone la primera intervención urbanística en la ciudad. Con la llegada de los musulmanes, posterior a la época visigoda en la que no se realizan grandes transformaciones, se realiza la construcción de algunas edificaciones entre las que destacan el Alcázar,
Huelva: Plano de delimitación del entorno de la Torre Canela (Ayamonte)

Huelva: Plano de delimitación del entorno de la Torre de Punta Umbría 


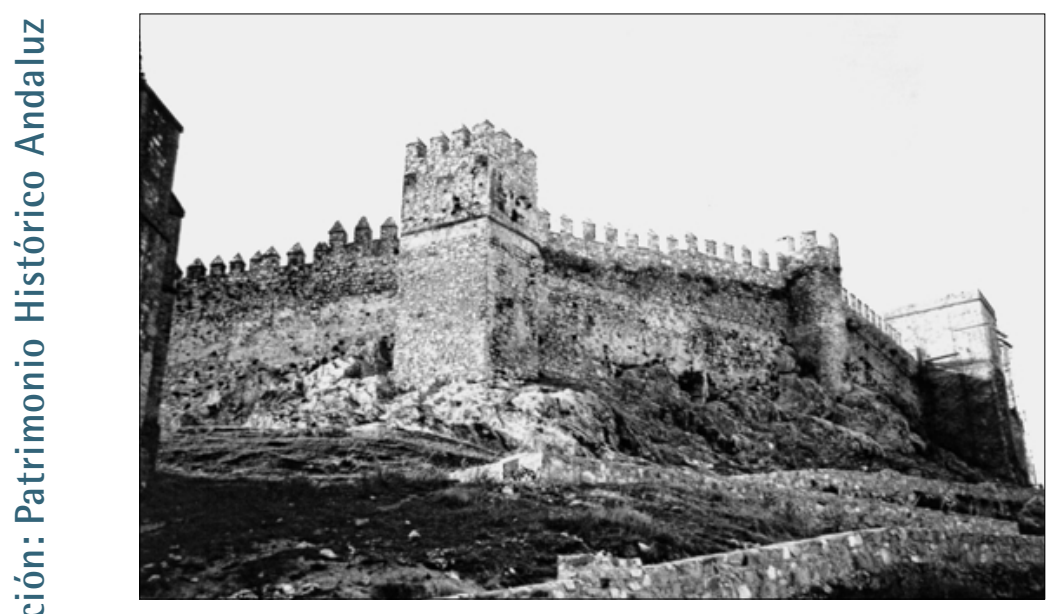

Huelva: Castillo de Santa Olalla del Cala

Huelva: Puerta de Sevilla. Conjunto Monumental de Niebla

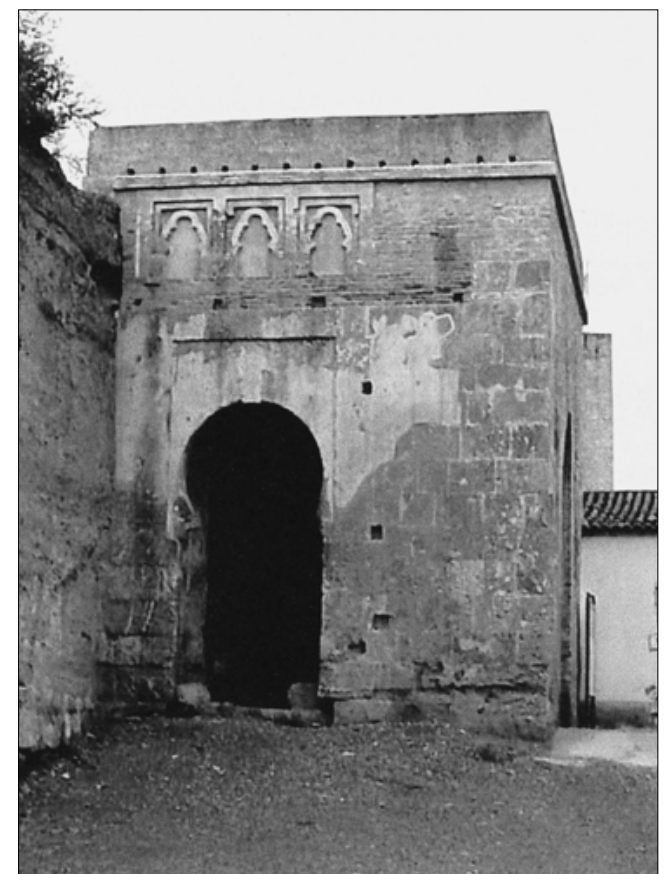

situado donde se emplaza el actual Castillo de los Guzmanes, y la Mezquita Mayor que es probable se situara donde la actual Iglesia de San Martín. Posteriormente y ante la creciente amenaza cristiana se procede a la ampliación de la muralla hacia poniente, estructurando la ampliación a partir del eje NOSE y su ortogonal, los cuales suponen el elemento generador del nuevo trazado urbano con características del urbanismo musulmán, transladándose el centro a la intersección de ambos ejes y construyéndose en él la nueva mezquita principal donde la actual Iglesia de la Granada, quedando como mezquita de barrio la anteriormente señalada. Aunque no se descartan reformas y ampliaciones de época califal y almorávide, el recinto que se nos muestra parece claramente de época almohade. Para finalizar el recorrido histórico Alfonso $X$ conquista el último reino musulmán al oeste de Al-Andalus y se construyen las Iglesias de Santa María, San Martín, San Miguel y Santiago, extramuros la de San Lorenzo. En esta época se destruye el alcázar árabe y se realiza el Castillo de los Guzmanes en 1474.
En el conjunto monumental de la ciudad de Niebla se han llevado a cabo actuaciones puntuales en la Iglesia de Nuestra Señora de la Granada, la Iglesia de San Martín, el Castillo de los Guzmanes y las Murallas. Debido al carácter aislado de estas últimas, se ha encargado desde la Consejería de Cultura a través de la Delegación Provincial de Huelva la realización de un Plan Director de Niebla que unifique criterios y englobe las actuaciones a realizar dentro de un proyecto común.

Con respecto a la restauración del Castillo de Aroche es preciso señalar que dicho castillo, de traza poligonal, presenta 10 lienzos jalonados por otras tantas torres de planta cuadrada, una de las cuales, la señalada como T2 en el plano, se reduce a un contrafuerte. En la actualidad carece de almenas y merlones, estando la mayoría de las torres cortadas a un nivel ligeramente inferior al del remate de los lienzos. Su cerca, cuyo perímetro tiene una longitud aproximada de $273 \mathrm{~m}$, es una de las más extensas de la provincia junto a las de Cumbres Mayores y Santa Olalla del Cala, presentando desde 1802 en su interior una plaza de toros. Hacia el suroeste se localizaba el acceso al castillo, la llamada Puerta de la Reina, su elemento más destacado y actualmente anulada, que exhibe externamente un arco de herradura apuntado con alfiz rehundido de ladrillo.

El origen árabe de la construcción se evidencia en su base constructiva de tapial y parece remontarse al siglo $X$, produciéndose en los siglos posteriores sucesivas reformas musulmanas y cristianas. Tras la conquista cristiana de la zona en el siglo XIII el castillo pasará a formar parte de la primera línea del sistema defensivo de la Banda Gallega, cumpliendo una función tanto militar como repobladora. En 1293 Sancho IV lo restaura, experimentando en los siglos posteriores sucesivas restauraciones debido a la contienda fronteriza con Portugal. Actualmente el castillo es sede del Punto de Información del Parque Natural de la Sierra de Aracena y Picos de Aroche.

Ante el delicado estado de conservación que presentaba el Castillo de Aroche, reflejado en el derrumbe el 23 de febrero de 200 I de un tercio de la torre señalada en el plano que se adjunta como TI, se efectuó en mayo de 200I un Informe Previo de las Obras de Emergencia a realizar, redactado por los arquitectos María Luisa Martín Martín y Pedro Rodríguez Pérez, y posteriormente la Ficha Diagnóstico, elaborada por los mismos arquitectos en noviembre de 2001.

El estado general del castillo es de deterioro grave, con presencia de vegetación, especialmente en las terrazas de las torres y la coronación y paramentos verticales de éstas y de los lienzos, acompañada de pérdida abundante de revestimientos, vaciado de juntas que da lugar a la caída de los materiales de la fábrica por acción directa de los agentes erosivos y la congelación invernal del agua retenida. El descalce progresivo de algunos lienzos y torres ha incidido asimismo en su precario estado de conservación, 
hecho agravado por el excesivo rebaje de la cota del terreno circundante para el aprovechamiento doméstico de las propiedades vecinas. Algunos lienzos han perdido en partes relativamente extensas de sus paramentos mampuesto o masa de tapia y tongadas de ladrillo, teniendo socavadas zonas concretas de sus arranques. Las torres más efectadas son, en orden decreciente, las que aparecen marcadas en el plano como TI, T3, T4, T5 y TIO.

La propuesta de actuación de la obra de emergencia que actualmente se está desarrollando en el castillo consiste en tres fases bien diferenciadas. En primer lugar la realización de trabajos previos consistentes en la limpieza y desbroce de las áreas de actuación exteriores al recinto; la limpieza, desbroce y picado de los paramentos de los lienzos y torres citados, así como del revestimiento de juntas; el apuntalamiento de las zonas en peligro de derrumbe; y el desmontaje de fábricas que por su inestabilidad no puedan ser consolidadas in situ. En segundo lugar se completan, refuerzan y reparan las fábricas de tapial, ladrillo y mampostería. Finalmente la actuación se completaría con la intervención en cubiertas y protecciones, consistente en la reparación de las terracillas de las torres y de la albardilla, así como del rejuntado de las fábricas de paramentos verticales, con la posterior aplicación de biocida para prolongar el estado de limpieza de todas las superficies exteriores de los cuerpos consolidados.

Paralelamente a la obra de emergencia, y con vistas a la restauración definitiva del castillo, se han encargado los estudios geotécnicos y de materiales, estudios históricos, levantamiento planimétrico y topográfico, y estudios arqueológicos del mismo, sumando todo ello una inversión total de 267.206,06 euros.

El Castillo de Cumbres Mayores forma parte del sistema defensivo de la "Banda Gallega". Dicha fortaleza, de planta irregular, está construida en mampostería con refuerzos de sillares y sillarejos en las esquina, alcanzando sus muros una altura de diez metros y un espesor de casi tres, siendo sus torres alternativamente rectangulares y semicirculares. La puerta principal, situada en el ángulo suroeste, es apuntada y se encuentra flanqueada por dos torreones unidos por un matacán corrido, siendo la estructura más compleja de todo el edificio. Posee, además, dos puertas menores o poternas, una mirando hacia el oeste y otra hacia el este, denominándose esta última Puerta del Sol y de la Luna por el relieve que ostenta. La cubierta que presenta la puerta principal es de cañón rebajado, algo apuntado, de pequeños sillares graníticos, siendo la única bóveda ejecutada totalmente en cantería en la serranía onubense. En las otras dos puertas secundarias las bóvedas son de cañón rebajado algo apuntado.

Podemos hablar de dos fases distintas en la construcción del castillo: una primera fase fundacional que corresponde a la mayor parte del edificio, fechada en 1293; y una segunda fase, fechada en el siglo XV, en
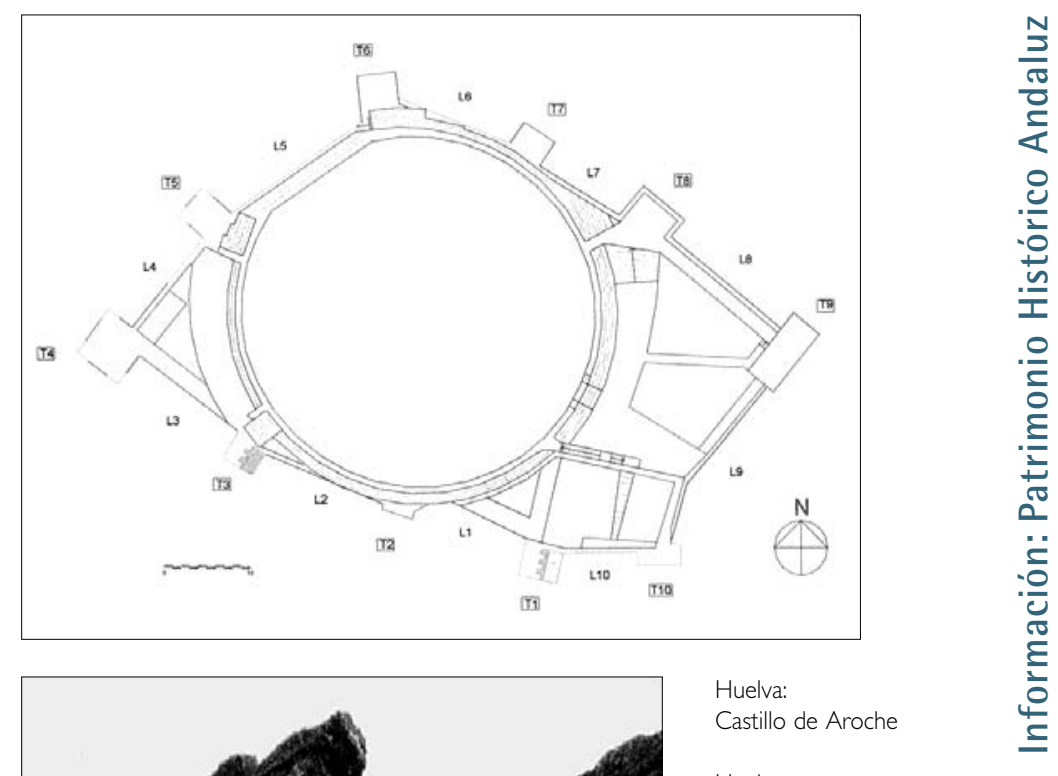

Huelva:

Torre I. Castillo de Aroche la que se producen algunas intervenciones como la unión de las cámaras superiores de las torres que flanquean la entrada principal y un probable reforzamiento del almenado de todo el contorno.

En base a todas las características del castillo anteriormente descritas se puede afirmar que estamos ante un tipo de fortificación totalmente apartado de la tradición islámica y que sus elementos estructurales y decorativos son indudablemente cristianos y góticos.

En el año 1999 se realizaron las labores de restauración del Castillo de Cumbres Mayores en base al proyecto realizado por el arquitecto Rafael Herrera Castillón con un presupuesto general que ascendió a 4 8.977,05 euros. Los objetivos principales de di- 


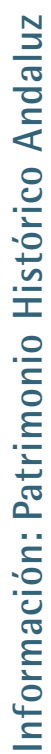

Huelva: Castillo de
Cumbres Mayores

Huelva: Maqueta del centro de interpretación del Castillo de Cumbres Mayores
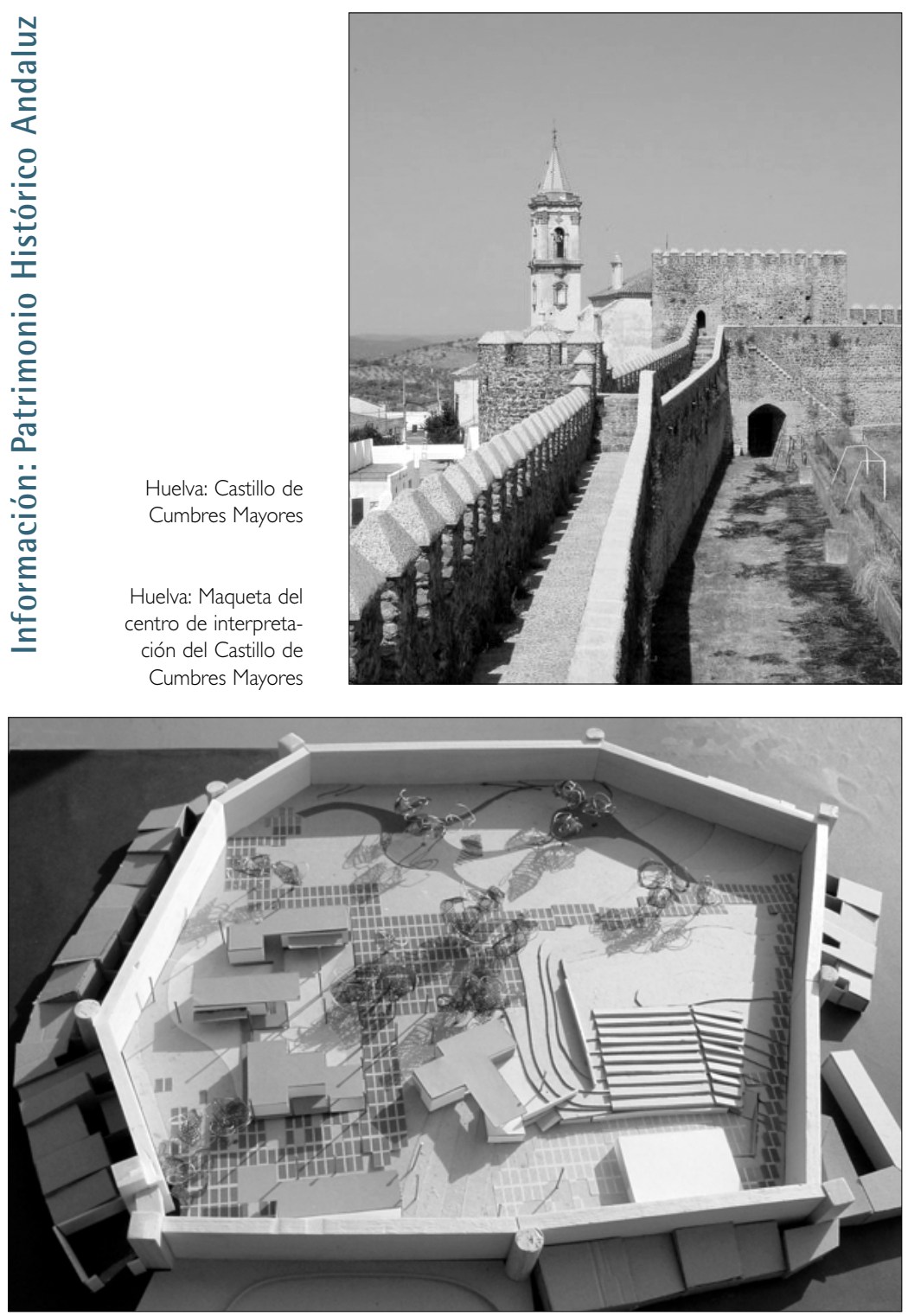

cha actuación consistieron en las reparaciones generales del castillo, las actuaciones en el acceso al mismo entre las que destacó la demolición del frente del acceso de reciente construcción, la rectificación de la alineación de fachada en la zona de la plaza de toros y, por último, la reparación de todo el pavimento con empedrado y guías de adoquines. En lo referente al conocimiento de las características constructivas del castillo, se realizaron una serie de catas arqueológicas en la zona de la entrada principal para ratificar que los muros situados delante de la puerta se construyeron simultáneamente al grueso del castillo, a continuación se llevó a cabo la demolición del acceso de reciente construcción antes nombrado y de las gradas y el cerramiento de la plaza de toros para conseguir la nueva alineación de fachada. Posteriormente se limpió la totalidad de los paramentos del recinto amurallado para eliminar la suciedad y los brotes vegetales parásitos con procedimientos no agresivos como cepillos vegetales y chorro de aire a presión moderada para no alterar ni remover la pátina de la piedra. En zonas concretas de mampostería y sillería se redujeron las grietas, reponiéndose piezas rotas y rejuntando con mortero similar al existente. De la misma forma se trataron los suelos del acceso principal y del paseo de ronda con piedras de la zona. En lo que respecta a la cantería se empleó piedra del lugar donde había que sustituir mampuestos o sillares, igualmente se rejuntaron las llagas con mortero bastardo y se anclaron las grietas con llaves de acero para garantizar su estabilidad. Asimismo algunas almenas que tenían ladrillo se desmontaron y sustituyeron por piedra igual a las circundantes. Las nuevas gradas de la plaza de toros se apoyaron sobre fábrica de un pie de ladrillo perforado y se realizaron con hormigón ciclópeo uniéndose al muro de fábrica mediante llaves de acero, asimismo se enfoscaron con mortero de cemento y se terminaron con hormigón de árido fino, superficie fratasada y bordes matados.

Tras las medidas de protección y conservación del patrimonio arquitectónico defensivo de la provincia de Huelva anteriormente expuestas resulta ineludible la DIFUSION del mismo para beneficio y conocimiento de los ciudadanos, buscando la concienciación e implicación de los mismos en su defensa, puesto que un patrimonio ignorado y desconocido es un patrimonio infravalorado y desaprovechado.

Una vez realizada la correspondiente restauración del Castillo de Cumbres Mayores, se plantea la necesidad de poner en valor dicho patrimonio y darle un uso para su divulgación en la sociedad. Por este motivo se encarga al mismo arquitecto redactor del proyecto, desde la Consejería de Cultura a través de la Delegación Provincial de Huelva, la realización de un Estudio de Aprovechamiento Interno del Castillo de Sancho IV, del cual se desprende la necesidad de la realización de un Centro de Interpretación del Territorio, planteado para establecer, coordinar y potenciar las labores de investigación, restauración y divulgación del Patrimonio Histórico en el territorio de la Sierra de Huelva. Dicho Centro de Interpretación estaría constituido por una serie de zonas destacando el Centro de Visitantes, el Centro de Estudios e Investigación y el Área de Actividades Culturales y Auditorio.

Una interesante forma de aprovechamiento de dicho patrimonio consiste en la utilización de estos inmuebles como lugares para la realización de espectáculos y celebraciones públicas como es el caso del Festival de Teatro y Danza de la Ciudad de Niebla, experiencia realizada anualmente en el Castillo de los Guzmanes de la citada localidad.

Desde la Delegación Provincial de Cultura de Huelva se está estudiando la posibilidad de realizar distintos itinerarios del patrimonio arquitectónico defensivo de la provincia. Con estas rutas se pretendería poner en valor un patrimonio hasta hace poco olvidado pero que sin duda ha marcado la identidad de las localidades en las que se ubica, pudiendo su conocimiento y difusión ayudar a potenciar el desarrollo del territorio en el que se asientan. 
La primera ruta consistiría en la "Ruta de las torres almenaras de la costa onubense", desde la Torre de San Jacinto hasta la Torre Canela o viceversa, realizándose distintos centros de interpretación de la citada ruta como el que se está desarrollando en la Torre de Punta Umbría.

La segunda sería la "Ruta de los castillos de la frontera con Portugal", desde Ayamonte cuyo castillo hoy parador- y Baluarte de las Angustias constituían parte del sistema defensivo creado en oposición al castillo de la localidad portuguesa de Castro Marín, pasando por Sanlúcar de Guadiana con el Castillo de San Marcos, construido para defender la localidad de la vecina villa portuguesa de Alcoutim; los castillos de Paymogo, Aroche y Cumbres de San
Bartolomé; y finalmente Encinasola con su castillo del que solo quedan algunos lienzos y los Baluartes de San Felipe, dedicado a Felipe II, y de San Juan, dedicado a don Juan de Austria.

La tercera y última ruta sería la denominada "Ruta de los Castillos de la Banda Gallega", que enlazaría con la anterior. En ella estarían comprendidos los castillos de las tres líneas defensivas de la que constaba, y que en páginas precedentes se ha detallado.

Todas estas actuaciones en materia de protección, conservación y difusión descritas a lo largo del presente artículo se conducen en la consideración de estos inmuebles como elementos simbólicos insustituibles para los municipios en los que se asientan.

Nota: Relacionada con el tema de la arquitectura defensiva de Andalucía, se encuentra la reseña sobre las Jornadas Medievales de Cortegana. Véase sección Noticias y Comentarios, al principio de este número.

\section{Bibliografía}

BAENA GALLÉ, J.M. Dos propuestas de itinerarios culturales en Andalucía Occidental sobre Arquitectura Militar. En PH, Boletín del Instituto Andaluz del Patrimonio Histórico $n^{\circ}$ 36. Sevilla, septiembre 200।, pp. 2 ||-2। 5 .

CASQUETE DE PRADO, N. Los castillos de la Sierra Norte de Sevilla en la Baja Edad Media. Sevilla: Diputación Provincial, 1993.

CASTILLO RUIZ, J. El entorno de los Bienes Inmuebles de Interés Cultural. Concepto, legislación y metodologías para su delimitación. Evolución histórica y situación actual. Granada: Universidad, 1997.

COLLANTES DE TERÁN Y DELORME, F. Los castillos del Reino de Sevilla. En Archivo Hispalense n58-59, Sevilla, 1967.

FALCÓN MÁRQUEZ, T. Faros y torres de almenara en el litoral andaluz. En Arquitectura e Iconografía artística militar en España y América (siglos XV-XVIII). Sevilla, 1999, pp. 339-353.

MORA FIGUEROA, L. Torres de almenara de la costa de Huelva. Huelva: Diputación Provincial, 1981.

MORALES MARTíNEZ, A.J. Arquitectura medieval en la Sierra de Aracena. Sevilla: Diputación Provincial, 1976.
PAVÓN MALDONADO, B. Arquitectura islámica y mudéjar en Huelva y su provincia. Huelva: Diputación Provincial, 1996.

PAZ SÁNCHEZ, J.J. Los miedos a la guerra. El castillo de Niebla. En MÁRQUEZ DOMÍNGUEZ, J.A. (dir.) Artes, costumbres y riquezas de la provincia de Huelva, vol. III. Madrid: Editorial Mediterráneo, 1998, pp. 857-872.

RODRÍGUEZ ESTÉVEZ, J.C. Las fortificaciones medievales en Andalucía Occidental. Un legado a conservar. En PH, Boletín del Instituto Andaluz del Patrimonio Histórico n³6. Sevilla, septiembre 200I, pp. 205-210.

SANCHA SORIA, F. Los castillos de la Banda Gallega. Aroche. En MÁRQUEZ DOMÍNGUEZ, J.A. (dir.) Historia de la provincia de Huelva, vol. I. Madrid: Editorial Mediterráneo, 1999, pp. 257-272.

SENRA GONZÁLEZ, S. Las torres almenara. Punta Umbría. En MÁRQUEZ DOMÍNGUEZ, J.A. (dir.) Historia de la provincia de Huelva, vol. II. Madrid: Editorial Mediterráneo, 1999, pp. 48I-496.

W.AA. Los castillos a través de la historia. Huelva. En Jornadas Europeas de Patrimonio Histórico. Sevilla: Consejería de Cultura, 1997. 